\title{
Abstract \\ Elucidating the Role of XRN2-Mediated DNA Repair Programs ${ }^{\dagger}$
}

\author{
Tuyen T. Dang * (D) and Julio C. Morales*
}

Stephenson Cancer Center, Department of Neurosurgery, University of Oklahoma Health Science Center, Oklahoma City, OK 73104, USA

* Correspondence: tuyen-dang@ouhsc.edu (T.T.D.); julio-morales@ouhsc.edu (J.C.M.)

+ Presented at the 1st International Electronic Conference on Cancers: Exploiting Cancer Vulnerability by Targeting the DNA Damage Response, 1-14 February 2021; Available online: https:/ /iecc2021.sciforum.net/.

Keywords: DNA damage; Glioblastoma; R loops

check for updates

Citation: Dang, T.T.; Morales, J.C. Elucidating the Role of XRN2-Mediated DNA Repair Programs. Med. Sci. Forum 2021, 3, 6. https://doi.org/ 10.3390/IECC2021-09210

Academic Editors: Nicola Curtin and Helen E. Bryant

Published: 29 January 2021

Publisher's Note: MDPI stays neutral with regard to jurisdictional claims in published maps and institutional affiliations.

Copyright: (c) 2021 by the authors. Licensee MDPI, Basel, Switzerland. This article is an open access article distributed under the terms and conditions of the Creative Commons Attribution (CC BY) license (https:// creativecommons.org/licenses/by/ $4.0 /)$.
Glioblastoma multiforme (GBM) is a highly aggressive brain cancer. The standard course of treatment is a combination of radiation and chemotherapy. Even with the dual treatment, the 5 -year survival rate of patients with GBM is between 4 and $7 \%$. Therefore, there is an urgent need to develop novel therapies to increase survivorship. A possible cause of the low survival rate for GBM patients is the presence of neoplastic cells with efficient DNA repair abilities. These cells have been shown to be resilient against chemotherapy and radiation. They often continue to grow unchecked leading to lethal secondary tumor disease.

XRN2 is upregulated in GBMs as compared to normal and other brain cancer types. XRN2 is a $5^{\prime}-3^{\prime}$ - exonuclease that resolves DNA:RNA hybrids (R loops) that arise during transcription, especially at the $3^{\prime}$ - end of genes. R-loop biology can affect gene expression by modulating the access of genes to transcription factors, miRNA transcription, and methylation status of genes. Our preliminary data show that the loss of XRN2 sensitizes to a variety of DNA damaging agents, particularly ionizing radiation. In addition, XRN2 is required for DNA repair in specifically DNA double-stranded break repair.

To understand how XRN2 modulates DNA repair, we conducted RNA-Seq analyses of two GBM cell lines with and without XRN2 expression and found that XRN2 can regulate genes involved in the DNA repair pathway. We conducted a mini-cherry-picked screen of the XRN2 targets and found at least six genes to be required for DNA double-stranded break repair. A subset of the six genes was also found to be sensitive to DNA damage agents such as ionizing radiation, etoposide, and Parp-1 inhibition. One XRN2-target is POLA2. We found that POLA2 is required for homologous recombination and nonhomologous end-joining repair, the two major repair pathways for DNA double-stranded breaks. Another XRN2 target is CENPI. We found that CENPI is required for homologous recombination repair and not non-homologous end-joining, showing that XRN2 targets have differential impacts in DNA repair.

Our goal is to develop a patient signature that can better predict patient outcomes and, if possible, a new synergetic treatment plan to increase the efficacy of radio-therapies.

Supplementary Materials: The following are available online at https:/ / www.mdpi.com/article/ 10.3390/IECC2021-09210/s1.

Institutional Review Board Statement: Not applicable.

Informed Consent Statement: Not applicable.

Data Availability Statement: These data can be found in our two publications on POLA2 and CENP-I. 